Artigo: O conceito de personalização de Lipovetsky como chave para entender a noção de pósverdade

\title{
O CONCEITO DE PERSONALIZAÇÃO DE LIPOVETSKY COMO CHAVE PARA ENTENDER A NOÇÃO DE PÓS-VERDADE
}

\author{
THE CONCEPT OF PERSONALISATION OF LIPOVETSKY AS KEY TO UNDERSTAND THE NOTION \\ OF POST-TRUTH
}

Fabiano veliq*

\begin{abstract}
RESUMO
O presente artigo tem em vista analisar a proposta de Gilles Lipovetsky que caracteriza a nossa época como hipermoderna a partir do processo de personalização. Procuramos evidenciar que tal processo de personalização conduz a um individualismo que se manifesta de forma nítida em uma dinâmica consumista interferindo na relação do sujeito com a sociedade e ao mesmo tempo procuramos evidenciar em que medida a pós-verdade é uma consequência direta desse processo. Para tal objetivo iniciamos com o tema do individualismo e como ele foi proposto por Louis Dumont; em seguida analisamos como o termo para caracterizar a nossa época se torna em si uma questão problemática a partir da visão de diversos autores, para depois focarmos no conceito de personalização formulado por Gilles Lipovetsky e tentar compreender em que medida esse processo conduz à noção de pósverdade e ao mesmo tempo pensar a tarefa da filosofia diante desse cenário.
\end{abstract}

PALAVRAS-CHAVE: Personalização. Individualismo. Hipermodernidade. Pós-verdade.

\section{ABSTRACT}

The present article aims to analyze the proposal of Gilles Lipovetsky that characterizes our time as the hypermodern era from the process of personalization. We try to show in this article that this process of personalization leads to an individualism that manifests itself clearly in a consumerist dynamic interfering in the relation of the subject with the society and at the same time we try to evidence to what extent the post-truth is a direct consequence of this process. For this purpose we began with the theme of individualism and as it was proposed by Louis Dumont, then we analyze how the term to characterize our age becomes a problematic issue from the perspective of several authors and then focus on the concept of personalization formulated by Gilles Lipovetsky to try to understand to what extent this process leads to the notion of post-truth and at the same time to think the task of philosophy before this scenario.

KEYWORDS: Personalization, Individualism, Hypermodernity. Pos-Truth.

O tema do individualismo é com certeza um tema bastante amplo, e seria muita pretensão nossa abarcar toda a discussão desde a sua gênese até o nosso contexto atual, passando por todas as nuances que o termo adquiriu desde a sua formulação por Louis Dumont que, como afirmamos acima, foi um dos primeiros sociólogos a trabalhar o conceito

\footnotetext{
* Mestre em Filosofia da Religião pela FAJE e Doutor em Psicologia pela PUC Minas. Doutorando em Filosofia pela UFMG. E-mail: veliqs@ gmail.com.
} 
de individualismo. Dumont (1985, p. 36) procurará entender a gênese e a evolução do individualismo na sociedade ocidental:

Eis a minha tese, em termos aproximados: algo do individualismo moderno está presente nos primeiros cristãos e no mundo que os cerca, mas não se trata exatamente do individualismo que nos é familiar. Na realidade, a antiga forma e a nova estão separadas por uma transformação tão radical e tão complexa que foram precisos nada menos de dezessete séculos de história cristã para completá-la, e talvez prossiga ainda em nossos dias. A Religião foi o fermento essencial, primeiro, na generalização da fórmula e, em seguida, na sua evolução. Nos nossos limites cronológicos, o pedigree do individualismo moderno é, por assim dizer, duplo: uma origem ou aceitação de uma certa espécie, e uma lenta transformação numa outra espécie.

Para Dumont, portanto, o gérmen do individualismo estaria mais próximo dos primeiros cristãos que de outras sociedades. De forma sucinta, para ele,

O individualismo cristão está presente desde a origem sendo que a evolução consiste em um movimento a partir de um individualismo-fora-do-mundo para o individualismo-no-mundo (de forma progressiva), processo no qual a comunidade holista mesma acaba por desaparecer, ou quase desaparece. (DUMONT, 2000, p. 27).

Assim, existiriam dois tipos de sociedade, segundo o autor: "Quando o Indivíduo constitui o valor supremo, falo de individualismo; no caso oposto, em que o valor se encontra na sociedade como um todo, falo de holismo.” (DUMONT, 1985, p. 37).

O grande problema para ele era investigar como de sociedades tipicamente holistas surgem sociedades de cunho individualista. Para isso, Dumont propõe uma comparação com a sociedade indiana, em que o caráter holista se mostra de forma bastante visível a partir do conceito de castas. Dumont (1992) analisará a sociedade indiana, mostrando como se dá a relação entre o indivíduo e a sociedade em uma sociedade tipicamente holista.

À medida que suas investigações vão se encaminhando, Dumont é capaz de afirmar que o princípio cristão de que o indivíduo é um ser-em-relação-com-Deus acaba colocando o indivíduo como um indivíduo-fora-do-mundo. A questão se coloca do ponto de vista de um individualismo absoluto, mas ao mesmo tempo em um universalismo absoluto em relação a Deus. A alma individual adquire valor em relação a Deus, e, a partir de uma relação filial dos membros que possuem um mesmo pai através da figura do Cristo, o cristianismo é capaz de desvalorizar o mundo em nome de uma filiação que transcende as instituições sociais. 
Artigo: O conceito de personalização de Lipovetsky como chave para entender a noção de pósverdade

A fraternidade em torno da figura do Cristo coloca todos os cristãos em um pé de igualdade que existe na presença de Deus. O indivíduo-fora-do-mundo se insere em uma comunidade que caminha na Terra, mas tem o seu coração no céu e, dessa forma, o individualismo cristão é capaz de subordinar o holismo. À medida que a Igreja passa a assumir o poder e pretende reinar direta e indiretamente sobre o mundo, o indivíduo cristão é chamado a se comprometer com esse mundo de forma completamente nova. O indivíduofora-do-mundo se transforma em um indivíduo-no-mundo. A exacerbação completa dessa proposta pode ser vista no interior da Teologia da Libertação dos anos 60 do século passado, quando o caráter imanente do mundo, em várias ocasiões, é ressaltado em detrimento da dimensão transcendente.

Esse grande período de transformação da Teologia, desde o início da era cristã até a Teologia da Libertação, não será algo trabalhado por nós no decorrer deste artigo. O que procuramos ressaltar a partir desse exemplo é apenas a dinâmica evidenciada por Dumont de uma passagem de um holismo a um individualismo iniciado pelo cristianismo.

Não é novidade para ninguém que a nossa época é fruto de inúmeras mudanças que ainda estão em movimento e, por isso, tornam-se difíceis de ser analisadas de forma mais imparcial. As inúmeras discussões sobre o que de fato caracterizaria a nossa sociedade atual é motivo de inúmeros debates em relação aos melhores termos que caracterizariam a nossa real situação.

Vários sociólogos, filósofos, cientistas políticos discutem sobre qual seria o melhor termo para caracterizar a nossa época. Contemporaneidade, pós-modernidade, hipermodernidade são termos extensamente debatidos por esses grupos em uma tentativa de definir a nossa época. Por mais importantes que sejam tais debates, eles não serão alvo de nossa análise neste trabalho. Quem tiver interesse nessa discussão, sugerimos o excelente livro de Krishan Kumar (1997), especialmente os capítulos quatro e cinco, em que o autor analisa de forma bastante cuidadosa os diversos termos, os principais defensores de determinado termo, além das justificativas para se adotar um termo em detrimento do outro.

O termo pós-modernidade aparece no final dos anos 70 advindo do discurso da Arquitetura, mas foi rapidamente assimilado pelo discurso das Ciências Sociais, pois indicava uma espécie de "abalo" dos alicerces absolutos e o fracasso das grandes ideologias da história. O que se constatava é que estávamos diante de um novo período histórico, em que a diversidade de opiniões e uma menor expectativa em relação ao futuro davam a tônica. $\mathrm{O}$ 
futuro como lugar de uma realização, como lugar de esperança era facilmente abandonado em nome de um enfoque cada vez maior no presente.

O termo "pós-moderno" visava definir esse novo momento de fixação no presente, salientando uma mudança de direção no caminho da sociedade e, ao mesmo tempo, indicar uma reorganização profunda do modo de funcionamento social.

No entanto, a expressão "pós-moderno" logo se via em apuros dada a sua ambiguidade e, ao mesmo tempo, o seu caráter um tanto quanto vago. O pós de pós-moderno ainda dirigia o seu olhar para o passado, ao mesmo tempo em que afirmava a sua morte. O que atestava isso era o fato de que não se podia falar em uma "mudança de direção", mas sim de uma exacerbação de um modo de vida que teve seu início nos anos 1920. Segundo Lipovetsky e Charles (2004, p. 52),

Há vinte anos, o conceito de pós-moderno dava oxigênio, sugeria o novo, uma bifurcação maior; hoje, entretanto, está um tanto quanto desusado. O ciclo pósmoderno se deu sob o signo da descompressão cool do social; agora, porém, temos a sensação de que os tempos voltam a endurecer-se, cobertos de nuvens escuras. [...] No momento em que triunfam a tecnologia genética, a globalização liberal e os direitos humanos, o rótulo pós-moderno já ganhou rugas, tendo esgotado sua capacidade de exprimir o mundo que se anuncia.

Se o termo pós-moderno não se aplica para entender nossa dinâmica atual dada a sua ambiguidade, Lipovetsky propõe o termo hipermodernidade para caracterizar uma época em que tudo é hiper: hipercapitalismo, hiperclasse, hiperindividualismo, hiperterrorismo. Segundo ele, a nossa época se caracteriza por ser uma modernidade elevada a uma potência superlativa, quando a modernização é desenfreada e o ímpeto técnico-científico alcança níveis inimagináveis, que carregam tantos perigos quanto promessas. Tudo acontecendo rapidamente, sem pausas e sem descanso:

\footnotetext{
Longe de decretar-se o óbito da modernidade, assiste-se a seu remate, concretizando-se no liberalismo globalizado, na mercantilização quase generalizada dos modos de vida, na exploração da razão instrumental até a "morte" desta, numa individualização galopante. (LIPOVETSKY; CHARLES, 2004, p. 53).
}

O que se vê, portanto, não seria tanto uma superação da modernidade, mas uma reconfiguração em que os valores modernos tais como a moral, a revolução, o ideal de Nação se perderam em grande parte, e as forças de oposição à modernidade democrática, liberal e individualista não são mais estruturantes, mas em que impera um individualismo e um 
Artigo: O conceito de personalização de Lipovetsky como chave para entender a noção de pósverdade

relativismo em relação a praticamente todas as coisas. O Estado, a Religião, a família se privatizam, enquanto a sociedade de mercado se impõe. Ainda segundo os autores,

Eleva-se uma segunda modernidade, desregulamentadora e globalizada, sem contrários, absolutamente moderna, alicerçando-se essencialmente em três axiomas constitutivos da própria modernidade anterior: o mercado, a eficiência técnica, o indivíduo. Tínhamos uma modernidade limitada; agora, é chegado o tempo da modernidade consumada. (LIPOVETSKY; CHARLES, 2004, p. 54).

A hipermodernidade se impõe hiperbolizando todas as coisas. Do consumo às viagens, da tecnologia à alimentação. Tudo se torna hiper no mundo onde as mudanças e o mercado sempre estão em crescimento, onde até os comportamentos individuais são levados ao extremo. Prova disso são os esportes em séries, as bulimias, anorexias, obesidades.

A época hipermoderna é também a época das contradições. Se por um lado os indivíduos cuidam cada vez mais do corpo obedecendo às instruções médicas, informando-se sobre o que devem ou não fazer, por outro lado, aumentam as doenças psíquicas, as patologias individuais, o anarquismo comportamental. Lei e liberdade desenganchadas em um quadro no qual o hiperindividualismo distanciado do outro toma lugar, ele também paradoxal, pois, ao mesmo tempo em que se mostra prudente e calculista (por exemplo, nas questões de saúde, do corpo etc.), ao mesmo tempo se mostra desregrado e caótico.

Segundo Lipovetsky e Charles (2004, p. 56-57),

Tudo se passa como se tivéssemos ido da era do pós para a era do hiper. Nasce uma nova sociedade moderna. Trata-se não mais de sair do mundo da tradição para aceder à racionalidade moderna, e sim de modernizar a própria modernidade, racionalizar a racionalização - ou seja, na realidade, destruir os "arcaísmos" e as rotinas burocráticas, pôr fim à rigidez institucional e aos entraves protecionistas, relocar, privatizar, estimular a concorrência. [...] Por toda a parte, a ênfase é na obrigação do movimento, a hipermudança sem o peso de qualquer visão utópica, ditada pelo imperativo da eficiência e pela necessidade da sobrevivência. Na hipermodernidade, não há escolha, não há alternativa, senão evoluir, acelerar para não ser ultrapassado pela "evolução": o culto da modernização técnica prevaleceu sobre a glorificação dos fins e dos ideais.

Podemos notar que a hipermodernidade se caracterizaria como um momento em que o excesso e o vazio se enfrentam em uma espécie de combate que gera, ao mesmo tempo, mais autonomia e liberdade ao sujeito, daí o seu caráter de "excesso", mas, em contrapartida, traz novas angústias e problemas e coloca o homem diante desse "novo lugar" que é, por definição, um lugar de vazio, por ser um lugar carente de referências. Isso porque o excesso 
de liberdade e autonomia acaba por colocar como objetos de questionamento todas as coisas, até mesmo as estruturas que organizam o mundo. Como observa Silva (2005, p. xi),

A era do vazio é um tempo de comunicação. Não mais da comunicação como conteúdo ou mensagem, no sentido moralizador desse termo, mas comunicação como forma de contato, expressão de desejos, emancipação do jogo utilitário. Gera medo, pânico e até horror uma época em que tudo pode ser questionado. Na realidade, essa desmontagem dos mecanismos de legitimação pela moral rigorista implica uma perda de poder pelos donos das sociedades ou um rearranjo das formas de controle: a manipulação cede lugar à sedução; a imposição deve transformar-se em conquista; cada um deve aderir a um valor, não mais ser obrigado a submeter-se a ele.

Ou ainda, nas palavras de Lipovetsky (2007, p. 196):

Devemos recusar tanto as Leituras pós-modernistas, como as Leituras de ficção científica ou de tendência apocalíptica do conforto contemporâneo. Na verdade, este último é simultaneamente high-tech e cultural, virtual e sensível, abstracto e táctil, funcional e emocional, dromocrático (Virilio) e estético. A ruptura face à primeira modernidade não foi, de modo algum, total; sob inúmeros aspectos, o nosso mundo não faz mais que levar ao extremo a dinâmica prometeica. Aquilo a que assistimos não é tanto o emergir de uma cultura "pós-moderna", mas fundamentalmente uma hipermodernização do conforto dominado pelo crescendo do tempo e da rapidez, pela excrescência do mercado e da oferta.

A chave de leitura lipovetskiana para analisar a hipermodernidade é o conceito de personalização. Para ele, a partir do momento em que as sociedades democráticas se desenvolvem, acontece um remodelamento constante e profundo dos setores da vida social. Esse processo é denominado como processo de personalização:

O processo de personalização procede de uma perspectiva comparativa e histórica, determina a linha diretiva, o senso do novo, o tipo de organização e de controle social que nos liberta da ordem disciplinar-revolucionária-convencional que prevaleceu até o decorrer da década de 1950. Ruptura com a fase inaugural das sociedades modernas, democráticas-disciplinares, universalistas-rigoristas, ideológicas-coercitivas, este é o sentido do processo de personalização [...] Trata-se de uma mutação sociológica global que está em curso, uma criação histórica próxima daquilo que Castoriadis chama de "significação imaginária central", combinação sinérgica de organizações e significados, de ações e valores, que vem se formando a partir da década de 1920 - apenas as esferas artísticas e psicanalíticas a anteciparam em alguns decênios - e que continuou a ampliar seus efeitos depois da segunda guerra mundial. (LIPOVESTKY, 2005, p. xvi).

Se por um lado tal processo de personalização se mostra como um avanço em direção a uma sociedade mais igualitária, mais flexível, baseada na informação e na consideração dos fatores humanos, negativamente tal processo remete à fratura da socialização disciplinar, 
Artigo: O conceito de personalização de Lipovetsky como chave para entender a noção de pósverdade

quando os valores são todos colocados em xeque, deixando esse indivíduo à mercê de si mesmo.

O processo de personalização é, portanto, uma nova maneira de a sociedade se organizar e se orientar, em que o que impera não é tanto a vinculação a uma determinada norma social, mas um processo em que as escolhas privadas são levadas ao extremo e o constrangimento deve sempre ser mínimo. O máximo de compreensão e o mínimo de coerção.

Ao invés de imergir o indivíduo dentro de regras uniformes de caráter moral, protecionista, o processo de personalização rompe com esse imaginário rigorista, cedendo lugar a novos valores que visam ao livre desenvolvimento da personalidade íntima, à legitimação do prazer, e agora à remodelagem das instituições de acordo com as aspirações dos indivíduos. O processo se inverte. Se, antes, a sociedade imperava sobre o indivíduo, agora o indivíduo quer que a sociedade seja de acordo com as suas aspirações.

\begin{abstract}
O ideal moderno de subordinação do indivíduo a regras racionais coletivas foi pulverizado, o processo de personalização promoveu e encarnou maciçamente um valor fundamental: o da realização pessoal, do respeito à singularidade subjetiva, da personalidade incomparável, quaisquer que sejam as novas formas de controle e de homogeneização realizadas simultaneamente. $\mathrm{O}$ direito de ser absolutamente si mesmo, de aproveitar a vida ao máximo é, certamente, inseparável de uma sociedade que instituiu o indivíduo livre como valor principal e não é mais do que a manifestação definitiva da ideologia individualista; mas foi a transformação dos estilos de vida ligada à revolução de consumo que permitiu esse desenvolvimento dos direitos e desejos do indivíduo, essa mutação na ordem dos valores individualistas. Salto adiante da lógica individualista: o direito à liberdade teoricamente ilimitado, mas até então circunscrito à economia, à política, à cultura ganha os costumes e o cotidiano. Viver livre e sem pressões, escolher seu modo de existência são os pontos mais significativos no social e no cultural do nosso tempo, pontos da aspiração, do direito mais legítimo aos olhos dos nossos contemporâneos. (LIPOVETSKY, 2005, p. xviii).
\end{abstract}

Ou ainda, segundo Bauman (1998, p. 10), o que caracterizaria a pós-modernidade seria a troca da segurança pela felicidade.

\begin{abstract}
Os homens e as mulheres pós-modernos trocaram um quinhão de suas possibilidades de segurança por um quinhão de felicidade. Os mal-estares da modernidade provinham de uma espécie de segurança que tolerava uma liberdade pequena demais na busca da felicidade individual. Os mal-estares da pós-modernidade provêm de uma espécie de liberdade de procura do prazer que tolera uma segurança individual pequena demais.
\end{abstract}

Essa nova configuração advinda do processo de personalização traz consigo um novo lugar para o indivíduo. Atualmente nenhum tipo de ideologia política é capaz de inflamar as 
multidões; os tabus, ainda que presentes, são mitigados a esferas privadas; os referenciais são perdidos, e o vazio domina o indivíduo; mas esse vazio de forma alguma é um vazio trágico, e sim um vazio que vê no hiperconsumo uma saída para tal situação.

A era do consumismo se instaura como espécie de tentativa de lidar com essa nova configuração. Consumismo não apenas de coisas, mas do próprio modo de existência. Consumos de lazer, viagens, psicologias etc. O que se busca é a qualidade de vida, sensibilidade ecológica, participações em feiras ao ar livre etc. O ideal do American way of life típico dos anos 20 do século passado é substituído por um novo ideal que tem no próprio indivíduo o seu alvo.

No mundo pós-moderno de estilos e padrões de vida livremente concorrentes, há ainda um severo teste de pureza que se requer seja transposto por todo aquele que solicite ser ali admitido: tem de mostrar-se capaz de ser seduzido pela infinita possibilidade e constante renovação promovida pelo mercado consumidor, de se regozijar com a sorte de vestir e despir identidades, de passar a vida na caça interminável de cada vez mais intensas sensações e cada vez mais inebriante experiência. (BAUMAN, 1998, p. 23).

O processo de personalização faz com que o individualismo se torne narcisista, isto é, o individualismo "limitado" se torne "total". No entanto, esse narcisismo não pode ser entendido como a instauração de um indivíduo monádico, mas ilustra para Lipovetsky outra dinâmica na hipermodernidade, que é o surgimento dos pequenos grupos com interesses comuns. Para o autor,

\begin{abstract}
O narcisismo não encontra seu verdadeiro sentido a não ser em uma escala histórica; no essencial, ele coincide com o processo tendencial que leva os indivíduos a reduzir a carga emocional investida no espaço público ou nas esferas transcendentes e, correlativamente, a aumentar as prioridades da esfera privada [...]. Do mesmo modo que o narcisismo não pode ser assimilado a uma estrita despolitização, ele é também inseparável de um entusiasmo relacional particular, como atesta a proliferação de associações, grupos de assistência e auxílio mútuo. A última figura do individualismo não reside numa independência soberana associal, mas sim nas ramificações e conexões em coletivos com interesses miniaturizados, hiperespecializados: reagrupamentos de viúvos, de pais de filhos homossexuais, de alcoólatras, de gagos, de mães lésbicas, de bulímicos. É preciso recolocar Narciso na ordem dos circuitos e redes integradas: solidariedade de pequenos grupos, participação e organização em trabalhos voluntários, "redes situacionais" não contradizem a hipótese do narcisismo, na verdade confirmam sua tendência. (LIPOVETSKY, 2005, p. xxii-Xxiii).
\end{abstract}

O individualismo que se inicia com o processo de personalização vê no narcisismo uma expressão dessa tendência social. $\mathrm{O}$ grande paradoxo é que, ao mesmo tempo em que o 
Artigo: O conceito de personalização de Lipovetsky como chave para entender a noção de pósverdade

individualismo cresce, a sociedade se torna mais global. Aumenta-se o consumo de massa, a comunicação atinge praticamente todos os setores da vida e o senso de "pertença" do indivíduo diminui. O indivíduo hipermoderno se mostra cada vez mais em um não lugar, fruto dessa nova configuração social. Em um espaço onde as ofertas são infinitas e os referenciais são cada vez menores, o indivíduo se encontra perdido, e é a partir disso que a sedução se torna a grande arma para o consumismo. O indivíduo que não é mais coagido a nada tem que ser fisgado a partir da sedução. Tal sedução visa respeitar as inclinações e desejos do indivíduo na oferta de produtos que satisfaçam exatamente o que ele procura. As ofertas são a la carte, são feitas customizadas para o indivíduo. Desde os pacotes de viagem até o próprio automóvel, passando pelos processos educativos, as terapias psicológicas, médicas, os medicamentos, tudo é montado de acordo com o desejo do indivíduo visando à sua necessidade particular. A sedução não poupa nenhum aspecto da vida desse indivíduo hipermoderno, que não é mais dominado no sentido estrito da palavra, mas é agora colocado em uma "teia soft" onde se ilude pensando ser livre no infinito de escolhas possíveis.

Essa constante possibilidade de fazer-se a cada momento tem como consequência direta o fato de "desengajar" o indivíduo do sentimento de continuidade e até mesmo do sentimento de um sentido. A indiferença cresce em todos os setores da vida cotidiana. A palavra do professor deixa de ser sagrada, torna-se banal e situa-se em pé de igualdade com a palavra da mídia; o trabalho não é mais o centro da vida do indivíduo. Em uma sociedade na qual $a$ incredulidade em relação aos metarrelatos - para usarmos a expressão de Lyotard (2004) - se faz presente de forma muito nítida, a apatia domina em todos os aspectos. Até mesmo movimentos como o retorno da esfera do sagrado, visíveis nas diversas novas formas de espiritualidades contemporâneas, indicam esse fluir apático da hipermodernidade. Segundo Lipovetsky (2005, p. 24),

\footnotetext{
O retorno do sagrado em si é atropelado pela celeridade e pela precariedade das existências individuais abandonadas a si mesmas. A indiferença pura designa a apoteose do temporário e do sincretismo individualista. Assim pode-se ser simultaneamente cosmopolita e regionalista, racionalista no trabalho e discípulo intermitente de determinado guru oriental; pode-se viver o momento permissivo e respeitar, de acordo com as necessidades, as prescrições religiosas. O indivíduo pósmoderno está desestabilizado e é, de certa maneira, "ubiquista".
}

Dessa forma, em um sistema que é organizado de acordo com o isolamento suave, “cool”, os ideais públicos não têm outra alternativa a não ser o enfraquecimento, permanecendo apenas a busca do ego e dos próprios interesses por parte do indivíduo. Um 
hiperinvestimento do privado e uma desmobilização do espaço público. Segundo Lipovetsky (2005, p. 33), vemos “o fim do homo politicus e surgimento do homo psychologicus".

A principal característica desse movimento é a perda do sentido histórico. Nasce, nesse momento, toda uma cultura hedonista e psicologista que tem como meta incitar à satisfação imediata das necessidades e à urgência de todos os prazeres. Hoje se vive para si mesmo sem se preocupar com as tradições e muito pouco com a posteridade. A perda do sentido da continuidade histórica é uma marca desse individualismo narcisista que se instaura na hipermodernidade. Ao mesmo tempo em que o futuro parece incerto, uma vez que a continuidade é colocada em xeque pelas constantes mudanças, o passado é desvalorizado por relembrar tradições e práticas arcaicas de controle. Esse indivíduo sem passado e sem futuro vê instaurar uma espécie de "narcisismo coletivo" que tem na apatia frívola uma de suas marcas mais visíveis. Desarraigado de tudo, esse indivíduo se encontra diante de um vazio e vê no autoinvestimento uma saída para tal vazio. Lipovetsky (2005, p. 34-35) afirma que

\begin{abstract}
$\mathrm{Na}$ verdade, o narcisismo foi gerado pela deserção generalizada dos valores e finalidades sociais, ocasionada pelo processo de personalização. A anulação dos grandes sistemas de sentidos e o hiperinvestimento do $\mathrm{Eu}$ andam de braços dados: nos sistemas com "aparência humana", que funcionam para o prazer, o bem-estar, a despadronização, tudo concorre para a promoção de um individualismo puro, ou seja, psicológico, desembaraçado dos enquadramentos de massa e projetado para a valorização geral do indivíduo. É a revolução das necessidades e sua ética hedonista que, atomizando suavemente os indivíduos e esvaziando aos poucos as finalidades sociais de seus significados profundos, permitiu que o discurso psi se enxertasse no social e se tornasse um novo éthos de massa; foi o "materialismo" exacerbado das sociedades da abundância que, paradoxalmente, tornou possível a eclosão de uma cultura centrada na expansão subjetiva, não por reação ou "suplemento de alma", mas, sim, por isolamento à escolha de cada um. [...] Longe de derivar de uma "tomada de consciência" desencantada, o narcisismo é o efeito do cruzamento entre uma lógica social individualista hedonista, impulsionada pelo universo dos objetos e dos sinais, e uma lógica terapêutica e psicológica, elaborada desde o século XIX a partir da aproximação psicopatológica.
\end{abstract}

Se a análise lipovetskiana estiver correta, podemos afirmar que, no momento em que o crescimento econômico cessa, vemos crescer o investimento psicológico, em que o indivíduo passa a consumir "consciência de si" em um movimento incessante de autoconhecimento. Narciso, agora identificado como homo psychologicus, é obcecado por si mesmo visando à sua independência de todo laço com o outro.

$\mathrm{O}$ autoconhecimento se torna a sina desse indivíduo, e daí pode-se perceber como a Psicanálise, com a noção de inconsciente, aparece como uma incrível ferramenta para esse indivíduo que precisa agora buscar, em uma aventura sem fim, se conhecer. Adentrar para as 
Artigo: O conceito de personalização de Lipovetsky como chave para entender a noção de pósverdade

sendas inconscientes em uma busca frenética por sua verdade. O narcisismo se desamarra de todos os entraves. A autoconsciência substitui a consciência de classe, ao mesmo tempo em que a consciência narcisista toma o lugar da consciência política. No entanto, quanto mais se investe nesse autoconhecimento, mais dúvidas aparecem a esse indivíduo, e a incerteza o domina. Sem referências de onde se ancorar, Narciso se coloca em órbita. O Eu aparece como um grande vazio devido ao hiperinvestimento a ele dedicado. Paradoxalmente, nada e tudo o aflige.

\begin{abstract}
A tese do "progresso" psicológico é insustentável diante da extensão e da generalização dos estados depressivos, outrora reservados em prioridade para as classes burguesas. Ninguém pode se vangloriar de escapar; a deserção social ocasionou uma democratização sem precedente da depressão, o tédio de viver, flagelo hoje em dia difundido e endêmico. Do mesmo modo, o homem "cool" não é mais sólido do que o homem do adestramento puritano ou disciplinar. Na verdade seria mais o inverso. Num sistema descaracterizado basta um simples acontecimento, um nada, para que a indiferença se generalize e ganhe existência própria. Atravessando sozinho o deserto, levando a si mesmo sem qualquer apoio transcendental, o homem de hoje se caracteriza pela vulnerabilidade. A generalização da depressão deve ser levada em conta não das vicissitudes psicológicas de cada um ou das "dificuldades" da vida atual, mas, sim, da deserção da res publica que foi limpando o terreno até o advento do indivíduo puro, do Narciso em busca de si mesmo, obcecado por si mesmo e, assim sendo, suscetível de enfraquecer ou de desmoronar a qualquer momento diante da adversidade que enfrenta desarmado, sem força exterior. O homem descontraído está desarmado. Os problemas pessoais assumem, assim, dimensões desmesuradas, e, quanto mais os contemplamos, ajudados ou não pelos psi, menos os resolvemos. Aqui se inclui o problema existencial, o ensino ou a política: quanto mais submetidos a tratamento e auscultação, mais os problemas se tornam insuperáveis. O que, hoje em dia, não está sujeito à dramatização e ao estresse? Envelhecer, engordar, enfeiar, dormir, educar os filhos, sair de férias... tudo se transforma em problema. As atividades elementares se tornaram impossíveis. (LIPOVETSTKY, 2005, p. 29-30).
\end{abstract}

Esse sentimento de não pertença a nada de sólido caracteriza aquilo que Bauman chamou de "sociedade líquida", que aponta para uma fragilidade das relações humanas. Nela, o Outro é esvaziado em toda a sua espessura, torna-se indiferente. Esse Outro aparece como um ser desafeiçoado que, várias vezes, será usado apenas como mero objeto de gozo.

Esse Outro desafeiçoado se torna indiferente, mas ao mesmo tempo algo a ser temido. $\mathrm{O}$ desapego emocional cada vez maior em nosso tempo indica esse temor. O medo de se decepcionar faz com que o indivíduo não entre em relação com esse Outro como uma espécie de fuga diante do sentimento. O sexo transformado em algo cool visa tentar eliminar a tensão que a relação sexual envolve, visando com isso um ar de indiferença e de desapego. Em vez da relação humana que envolve um descortinar-se para o Outro por parte do indivíduo, Narciso prefere a busca de uma "experiência forte", em que amar e vibrar se encontram de 
maneira rápida e solitária. Nessa busca, o que encontra é a própria desolação e nada além disso.

O individualismo narcisista emerge e coloca o indivíduo diante desse grande vazio em que nenhuma referência se mostra sólida o bastante para sustentá-lo. Se o passado como senso histórico, tradição, pertença a um lugar se perdeu, se o futuro gera mais medo que esperança, o Outro aparece como algo a ser temido em vez de alguém a ser buscado; resta a esse indivíduo uma busca desenfreada por si mesmo, tornando tudo a seu redor mero algo a ser consumido para tentar aplacar o vazio que o assola.

Nesse contexto podemos dizer que a nossa época acaba por realizar um caminho oposto ao proposto por Platão. No lugar de sairmos da doxa em direção à episteme, caminhamos da episteme em direção à doxa.

Como já comentamos, a nossa época hipermoderna se caracteriza por aquilo que Lyotard chamou de época da queda dos metarrelatos, ou seja, uma época em que as instituições, ou os discursos que organizavam a vida do sujeito passaram a não mais fazer sentido, perderam o seu caráter explicativo, etc. Se antes o acesso do sujeito à realidade se daria permeado por esses metarrelatos, hoje com a queda deles, a relação do sujeito com a realidade se dá de forma não mediada por esses discursos. Basicamente a segurança oferecida por tais discursos é refutada em nome da liberdade de poder cada sujeito criar o seu próprio discurso. Esse é o famoso drama apontado por Bauman de que a grande questão contemporânea seria de fato encontrar uma forma de fechar a equação entre "segurança" e "liberdade", pois quanto mais se tem segurança, menos se tem liberdade, e quanto mais se tem liberdade, menos se tem segurança (BAUMAN; LYON, 2013).

Se por um lado os metarrelatos ofereciam a segurança para o sujeito lidar com o mundo, entrando nele por meio de discursos já pré-estabelecidos, ao mesmo tempo eles cerceavam o sujeito de várias coisas. O sujeito pagava a segurança que os metarrelatos garantiam com uma diminuição da liberdade. Os movimentos contestatórios da década de 60 contestam exatamente esses discursos "aprisionadores" tais como a "religião", "família", "estado", "política", etc. como instituições que limitam a liberdade do sujeito e por isso devem ser eliminadas para que o sujeito possa de fato ser livre. Dessa forma abrem mão da segurança que os discursos proporcionavam em nome da liberdade de ser quem quiser, fazer o que quiser etc.

Concomitante a isso vemos o crescimento e o aprofundamento do capitalismo e o surgimento daquilo que ficou conhecido como "capitalismo tardio", ou seja, o capitalismo pós 
Artigo: O conceito de personalização de Lipovetsky como chave para entender a noção de pósverdade

década de 70 em que as relações de consumo já estão extremamente consolidadas, e o capitalista se torna muito mais um capitalista especulativo do que propriamente um capitalista que simplesmente "detém os meios de produção". Esse refinamento da posição do capitalista contemporâneo, aliado à disseminação massiva da ideologia consumista em todas as esferas da sociedade coloca esse sujeito sem metarrelatos em uma situação extremamente conflituosa e angustiante. Diante das diversas opções de consumo e sem nada para regular o seu gozo, o que resta para tal sujeito é apenas a sua opinião, os seus gostos pessoais como forma de lidar com as diversas demandas da vida cotidiana. Na queda dos metarrelatos a própria noção de "verdade" se perde, e o sujeito da nossa época é aquele que toma como verdade basicamente a sua opinião sobre um determinado fato.

A partir do momento em que a própria noção de verdade se torna obsoleta, o que vemos acontecer é a propagação daquilo que o dicionário Oxford definiu como palavra do ano de 2016, que é o conceito de "pós-verdade", ou seja, a predominância da opinião do sujeito sobre os fatos. Não importam os fatos, o que importa é apenas a opinião do sujeito, o que ele resolve acreditar, e cada vez mais o diálogo se torna extremamente impossível pois o que se percebe a cada dia é uma resistência muito grande para o debate, para a argumentação, e isso se evidencia em todas as esferas da vida cotidiana. Desde assuntos menos sérios até assuntos mais complexos, a preguiça para o diálogo, a apropriação de frases prontas sem reflexão, a tentativa de "igualação de discursos" como forma de evitar o debate são práticas extremamente comuns a quem tenta qualquer tipo de debate.

Na religião e na política esse tipo de argumento se sobressai na maioria das vezes e podemos afirmar que estão envolvidos nessa dinâmica a recusa de toda forma sistemática de diferenciação de discursos e o abrir mão do caráter dialogal do debate em nome de uma "saída fácil" para questões complexas. Não seria esse o grande sintoma contemporâneo da eliminação do diferente em nome de uma pseudoaceitação de todos em um processo de igualação que longe de "aceitar o diferente" o elimina no seu núcleo mais profundo?

Nessa recusa do diálogo vemos acontecer o inverso daquilo que Platão propunha que deveria ser o caminho para o conhecimento. Na época da hiperespecialização em que o conhecimento se torna extremamente ramificado, hiperespecializado, é impossível para qualquer indivíduo manter-se atualizado em todas as áreas mas, paradoxalmente, dele são exigidas respostas para todas as questões do seu tempo, desde questões éticas como aborto, eutanásia, a questões políticas, religiosas, familiares, etc. O sentimento de preguiça (ou má-fé) toma conta do indivíduo de forma que ele se recusa a pensar de fato as coisas e passa a 
assumir apenas a sua opinião como balizas para todas as questões, fechando-se para o diálogo que o levaria a sair da sua opinião em direção ao conhecimento. Curiosamente a proposta platônica de saída da doxa rumo a episteme envolve exatamente esse caráter dialogal, e era de se esperar que em uma era "pós-iluminista", "esclarecida" o diálogo fosse de fato algo que a maioria das pessoas estivesse disposta a realizar. No entanto, cada dia o que se vê é o oposto. O sujeito contemporâneo caminha a passos largos para o interior da caverna onde reina a opinião e, afastando-se do diálogo, recusa a conhecer as coisas nas suas nuances mais profundas.

Nesse sentido a filosofia se torna cada vez mais desprezada, mas cada vez mais necessária. Em uma época em que a noção de verdade se perdeu e se transformou em uma questão de opinião, resgatar a noção de verdade, não como verdade absoluta (segundo Platão e alas mais conservadoras do cristianismo e outras religiões), mas como noção orientadora do diálogo, torna-se novamente uma tarefa árdua para a filosofia. Pensamos que sem se resgatar essa noção a tendência são discursos cada vez mais polarizados, cada vez mais conservadores, mais rígidos, em que a vida vai se perdendo e discursos cada vez mais "totalitários" vão aparecendo.

Podemos dizer que a tarefa da filosofia na contemporaneidade continua árdua mas extremamente necessária em um mundo em que a pós-verdade reina.

\section{REFERÊNCIAS}

ALVES, Rubem. O enigma da religião. 6. ed. Campinas: Papirus, 2007.

BAUMAN, Zygmunt. O mal-estar da pós-modernidade. Rio de Janeiro: Jorge Zahar, 1998.

BAUMAN, Zygmunt; LYON, David. Vigilância líquida: diálogos com David Lyon. Rio de Janeiro: Zahar, 2013.

BÍBLIA SAGRADA. Tradução King James. Disponível em: https://www.bibliaonline.com.br/kjv. Acesso em: 01 abr. 2019.

DUMONT, Louis. Homo aequalis: gênese e plenitude da ideologia econômica. Tradução de José Leonardo Nascimento. Bauru: EDUSC, 2000.

DUMONT, Louis. Homo hierarchicus: o sistema das castas e suas implicações. São Paulo: EDUSP, 1992.

DUMONT, Louis. O individualismo: uma perspectiva antropológica da ideologia moderna. Rio de Janeiro: Rocco, 1985. 
Artigo: O conceito de personalização de Lipovetsky como chave para entender a noção de pósverdade

KUMAR, Krishan. Da sociedade pós-industrial à pós-moderna. Novas teorias sobre o mundo contemporâneo. Tradução de Ruy Jungmann. Rio de Janeiro: Jorge Zahar, 1997.

LIPOVETSKY, Gilles; CHARLES, Sébastien. Os tempos hipermodernos. São Paulo: Barcarolla, 2004.

LIPOVETSKY, Gilles. A era do vazio: ensaios sobre o individualismo contemporâneo. Tradução de Therezinha Monteiro Deutsch. Barueri: Manole, 2005.

LIPOVETSKY, Gilles. A felicidade paradoxal: ensaio sobre a sociedade de hiperconsumo. São Paulo: Companhia das Letras, 2007.

LYOTARD, Jean-François. A condição pós-moderna. Rio de Janeiro: José Olympio. 2004.

MARX, Karl; ENGELS, Friedrich. A ideologia alemã. 2. ed. São Paulo: Editora Ciências humanas, 1979.

MARX, Karl. Manuscritos econômicos filosóficos. In: FROMM, Erich. O conceito marxista de homem. Rio de Janeiro: Zahar Editores, 1964.

SILVA, Juremir Machado da. Apresentação: vazio e comunicação na era "pós-tudo". In: LIPOVETSKY, Gilles. A era do vazio: ensaios sobre o individualismo contemporâneo. Tradução de Therezinha Monteiro Deutsch. Barueri: Manole, 2005. p. ix-xiv. 